\title{
Health Care-Related Infections in Solid Organ Transplants
}

\author{
Sola A.F. ${ }^{1,2}$, Bittencourt A.R.C. ${ }^{2}$, Guerra C.M. ${ }^{3}$, Godoy H.L. ${ }^{3}$ and Medeiros E.A.S. ${ }^{1,3}$ \\ ${ }^{1}$ Healthcare Epidemiology Committee, Division of Infectious Diseases, Federal University of São Paulo; ${ }^{2}$ Department of Nursing - Federal \\ University of Sao Paulo; ${ }^{3}$ Department of Medicine - Federal University of Sao Paulo; São Paulo, SP, Brazil
}

\begin{abstract}
The health care-related infections are well-known in a critical care setting, but reports of those infections in solid organ transplanted patients are scarce. We developed a study of retrospective cohort in a tertiary teaching hospital for 14 months. Eighty-one patients underwent solid organ transplants. The global incidence of health care-related infection was $\mathbf{4 2 . 0 \%}$. Fifteen percent of the cases were occurrences of surgical site infections, $14.0 \%$ pneumonias, 9.0\% primary blood stream infections, $\mathbf{4 . 0 \%}$ urinary tract infections and $\mathbf{2 . 0 \%}$ skin infection. The most prevalent etiologic agents were $K$. pneumoniae $(\mathbf{8 . 6 \%})$, P. aeruginosa $(\mathbf{7 . 4 \% )}$; A. baumannii $(5.0 \%)$ and $S$. aureus $(2.5 \%)$. Mortality was $\mathbf{1 8 . 0 \%}$, none of then related to health care infections. The high rate of those infections, mainly surgical site infections, suggests a demand for stricter measures to prevent and control health care-related infections. Key-Words: Transplantation, health care-related infections, immunocompromised patients, infection control.
\end{abstract}

Solid organ transplant became, in the last few decades, an uncontested therapeutic option to several terminal diseases. Advances on surgical techniques and immunosuppression allowed the carrying out of over 24,000 transplants per year, in the USA [1].

Several Brazilian medical centers perform solid organ transplants with results similar to those found in the medical literature, and the number of procedures has increased in the last decade thanks to governmental policies [2].

Despite advances in immunosuppression, prophylaxis and early diagnosis, incidence of infectious complications remain high and they have been associated with loss of graft function and increased mortality [3].

Health care-related infections have been reported as a regular complication in severely ill recipients of solid organ transplants, facilitated by the use of invasive procedures, associated diseases and immunosuppression treatment.

Bacteremia and septic shock remain important causes of mortality in solid organ recipients. In 2005, Candel et al. communicated a series of 466 bacteremia episodes in 382 recipients and 66 episodes of septic shock (14.0\%) after several types of transplant recipients [4]. Singh et al. reported that $50.0 \%$ of all blood stream infections found in liver transplant recipients occur in the first month after the procedure [5], similar results were found by Rodriguez et al. among heart transplanted patients [6].

Sénéchal et al. found $6.5 \%$ incidence of surgical site infection after heart transplantation with a mortality rate of 6.7\%. Staphylococcus species were cultured intraoperatively from the majority of the patients [7].

Received on 28 June 2007; revised 20 October 2007.

Address for correspondence: Dr. Angela Figueiredo Sola. Healthcare Epidemiology Committee, Division of Infectious Diseases, Ferderal University of Sao Paulo, São Paulo, SP. Rua Armando Sales de Oliveira, 81 apto 01, Boqueirão. Zip code: 11050-070 Santos, SP, Brazil. Email: angelasola@gmail.com.

The Brazilian Journal of Infectious Diseases 2007;11(6):567-570. (C) 2007 by The Brazilian Journal of Infectious Diseases and Contexto Publishing. All rights reserved.
Although many papers review the whole spectrum of infections in solid organ transplant recipients, few specifically emphasize the first days after the procedure and the infections related to health care.

\section{Material and Methods}

Data in this study arose from a retrospective chart review of 81 consecutive solid organs transplants (heart, liver, kidney and double kidney and pancreas) performed between January 2004 and March 2005 at São Paulo Hospital, a 700-bed tertiary teaching hospital.

The epidemiological surveillance of the health carerelated infections was performed by a specific appliance of the National Nosocomial Surveillance System (NNISS) methodology [5,8]. An infection control professional diagnosed each infection according to standardized diagnosis of the Center for Disease Control and Prevention (CDC) criteria.

All infections diagnosed between the procedure and the 30 -first days after the surgery have been included in this review. Patients with infections are referred as a case. A control group was obtained with transplanted patients without diagnosis of infections.

Measures of significances were assessed by a univariate analysis. Chi-square, Fischer's exact test and Wilcoxon's test were used as appropriate. A multivariable analysis (logistic regression) was performed when possible. A p value $<0.05$ was considered statistically significant for all tests.

\section{Results}

During the period of study, were performed 35 double kidney and pancreas transplants (43.2\%), 20 heart transplants (24.7\%), 17 liver transplants $(21.0 \%)$, and nine kidney transplants $(11.1 \%)$. As show in Table 2, cases and controls were not different in respect to gender, age and preoperative stay. The only difference found was an expected higher surgical risk index (IRIC) score among cases $(\mathrm{p}=0.034)$. Surgery length time in the different transplant sites are shown in Table 1. 
The length of the pre-transplant period was longer in heart transplant patients than in the patients of other transplant sites ( 8.7 days; range $0-153$ days) but the incidence of HCRI was not different among them, even when the pre-transplant period was longer than 30 days $(p=0.486$ ) (Figure 1$)$.

The mortality rate during the first 30 post-transplant days was $18.6 \%$ in control group and $13.6 \%$ in case group ( $\mathrm{p}=$ 0.151 ), none due to infection (Table 2).

Thirty four episodes of HCRI were diagnosed among 81 recipients (global incidence of 42.0\%). The incidence rate by patient of HCRI was 27.0\% (34 HCRI episodes in 22 patients). Table 3 shows the spread of the infections by transplant site.

Fifteen percent of the HCRI were surgical site infections, $14.0 \%$ pneumonias, $9.0 \%$ primary bloodstream infections, $4.0 \%$ urinary tract infections and $2.0 \%$ skin infections. Surgical site infection was more common in double kidney-pancreas recipients (OR 10.5; IC 2.23-49.52; $\mathrm{p}=0.05$ ) and primary blood stream infections among liver recipients (OR 6.79; IC 1.0643.36; $\mathrm{p}=0.009$ ).
The most prevalent etiologic agents were $K$. pneumoniae (8.6\%), P. aeruginosa (7.4\%); A. baumannii $(5.0 \%)$ and $S$. aureus $(2.5 \%)$. No significant pattern of microorganism was identified among the different solid organ recipients (Table 4).

\section{Discussion}

Despite the extensive literature about infectious complications in solid organ transplants patients, there are very few studies that emphasize on the health care-related infections.

Regarding patients submitted to liver transplant, the incidence of health care-related infections in our study, by infection site, was similar to literature [9]. About the agents, there was no incidence of Gram-positive bacteria, in accordance to other reports [6].

Montoya et al. reported, in heart transplant, that main bacterial infection sites were the lungs and urinary tract [10]. In our study, however, the most observed episode of

Table 1. Surgical procedures time

\begin{tabular}{cccccc}
\hline Surgical procedures time & Heart & Kidney & Double kidney-pancreas & Liver & Total \\
\hline$<5 \mathrm{~h}$ & 2 & 8 & 0 & 1 & 11 \\
$5 \mathrm{~h}$ & 7 & 0 & 6 & 0 & 13 \\
$6 \mathrm{~h}$ & 3 & 0 & 10 & 0 & 13 \\
$7 \mathrm{~h}$ & 1 & 0 & 11 & 0 & 12 \\
$8 \mathrm{~h}$ & 4 & 0 & 6 & 3 & 13 \\
$9 \mathrm{~h}$ & 1 & 0 & 0 & 4 & 5 \\
$>10 \mathrm{~h}$ & 2 & 1 & 1 & 6 & 10 \\
\hline
\end{tabular}

Figure 1. Preoperative stay by solid organ transplant site (means and $95.0 \%$ confidence interval).

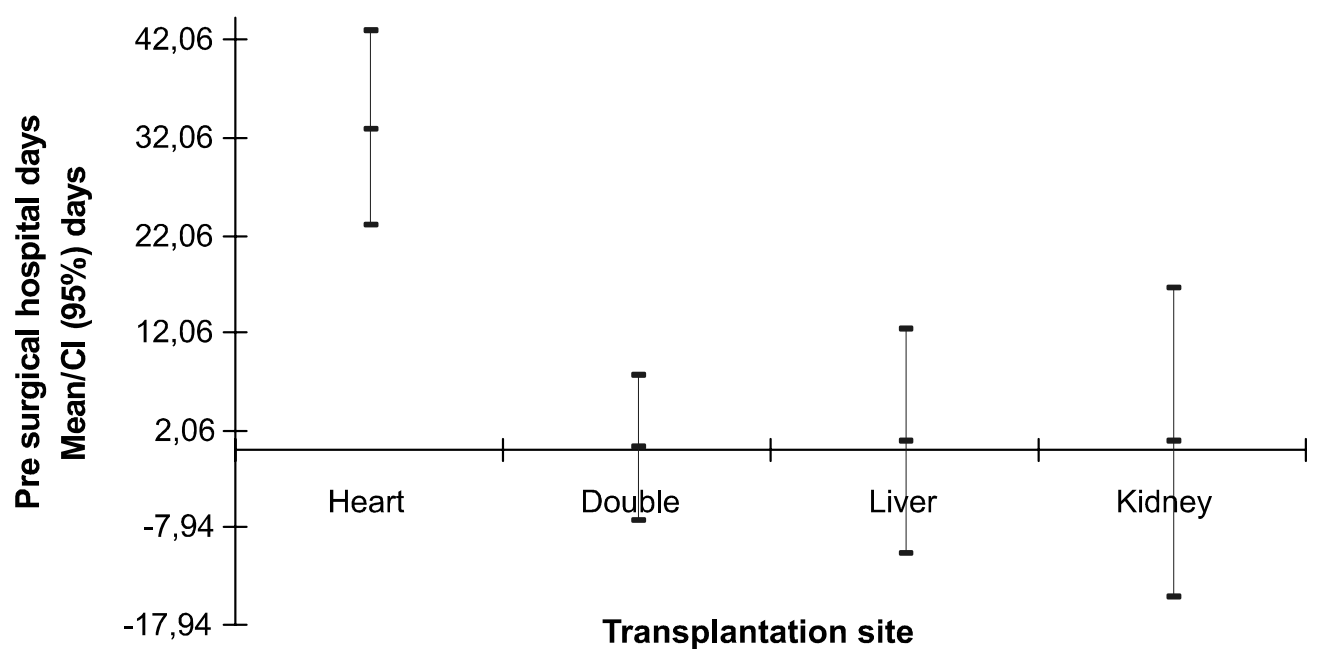


Table 2. Characteristics of cases and controls

\begin{tabular}{|c|c|c|c|c|c|c|}
\hline & & Case & Control & $\mathbf{p}^{+}$ & OR & CI \\
\hline Total $(\%)$ & & $22(27.1 \%)$ & $59(72.8 \%)$ & - & - & - \\
\hline Male (\%) & & $11(50 \%)$ & $31(52.5 \%)$ & NS & - & \\
\hline Age (y) & & $36.1 \pm 12.5^{*}$ & $36.9 \pm 12.7^{*}$ & NS & - & \\
\hline Preoperative stay (\%) & & $27.3 \%$ & $40.7 \%$ & NS & - & \\
\hline Mean preoperative stay $(d)$ & & $8.9 \pm 26.4^{*}$ & $2.8 \pm 16.1^{*}$ & NS & - & \\
\hline $\operatorname{IRIC}(\%)$ & & & & - & & \\
\hline & 0 & $1(20.0 \%)$ & $4(80.0 \%)$ & NS & & \\
\hline & 1 & $4(12.9 \%)$ & $27(87.1 \%)$ & 0.02 & 4.05 & 1.3-12.4 \\
\hline & 2 & $17(39.5 \%)$ & $26(60.5 \%)$ & 0.014 & 3.15 & $1.2-8.3$ \\
\hline Mortality (\%) & & $3(13.6 \%)$ & $11(18.6 \%)$ & NS & & \\
\hline
\end{tabular}

*Standard deviation; ${ }^{+}$Chi-square; NS=not significant; OR=odds ratio/CI confidence interval $(95 \%)$.

Table 3. Infection spread by transplant site

\begin{tabular}{lcccccccc}
\hline & Total & $\begin{array}{c}\text { Heart } \\
\mathbf{N = 2 0}\end{array}$ & $\begin{array}{c}\text { Kidney } \\
\mathbf{N = 9}\end{array}$ & $\begin{array}{c}\text { Double } \\
\text { Kidney- } \\
\text { Pancreas } \\
\mathbf{N = 3 5}\end{array}$ & $\begin{array}{c}\text { Liver } \\
\mathbf{N = 1 7}\end{array}$ & p value & $\begin{array}{c}\text { Odds } \\
\text { ratio }\end{array}$ & CI (95.0\%) \\
\hline Surgical site & $12(15 \%)$ & $4(20 \%)$ & 0 & $7(20 \%)$ & $1(6 \%)$ & 0.009 & 10.5 & $2.23-49.52$ \\
Pneumonia & $11(14 \%)$ & $3(15 \%)$ & 0 & $1(3 \%)$ & $7(41 \%)$ & NS & NS & NS \\
Urinary tract & $3(4 \%)$ & 0 & $1(11 \%)$ & $2(6 \%)$ & 0 & NS & NS & NS \\
Primary bloodstream & $7(9 \%)$ & $1(5 \%)$ & 0 & $1(3 \%)$ & $5(29 \%)$ & 0.05 & 6.79 & $1.06-43.36$ \\
Skin & $1(2 \%)$ & $1(5 \%)$ & 0 & 0 & 0 & NS & NS & NS \\
Total & 34 & $9(45 \%)$ & $1(11 \%)$ & $11(31 \%)$ & $13(76 \%)$ & NS & NS & NS \\
\hline
\end{tabular}

* Standard deviation; ${ }^{+}$Chi-square; NS=not significant; OR=odds ratio; CI confidence interval $(95 \%)$

Table 4. Microorganism spread by site of infection

\begin{tabular}{lccccc}
\hline & K. pneumoniae & P. aeruginosa & A. baumannii & S. aureus & p value \\
\hline Surgical site & 0 & $1(25 \%)$ & $1(25 \%)$ & $2(50 \%)$ & NS \\
Pneumonia & $3(60 \%)$ & $1(20 \%)$ & $1(20 \%)$ & 0 & NS \\
Urinary tract & $2(66.6 \%)$ & $1(33.4 \%)$ & 0 & 0 & NS \\
Primary bloodstream & $2(33.3 \%)$ & $2(33.3 \%)$ & $2(33.3 \%)$ & 0 & NS \\
Total & 7 & 5 & 4 & 2 & NS \\
\hline
\end{tabular}

NS=not significant.

HCRI was surgical site infection (20.0\%), an incidence rate higher than other studies, whose range varies from $3.5 \%$ to $6.5 \%[7,11]$.

Also, we found a long preoperative time in heart transplant recipients. Similar to literature, our terminal heart failure patients had a high rate of use of vasoactive drugs, mechanic ventricular support and indwelling catheters [12]. Unexpectedly, preoperative time was not identified as an infection risk factor.

In kidney and double kidney and pancreas transplantation, a low incidence of urinary tract infection was found, which was the most common infection complication related in the literature $[11,13]$. However, in the double kidney and pancreas transplantation we found, again, a high incidence of surgical site infection.

The ASA index, the potential contamination of the surgical incision, and the length of surgery may interfere on the incidence of surgical site infections. These variables are appraised separately and graded by the surgical risk index. The higher the risk Index, the greater the expected surgical site infection risk, as confirmed in our study.

Patients submitted to solid organ transplant, in general, have high ASA scores, due to comorbidities, and low potential for contamination of the surgical incision, since most surgeries are clean or only potentially contaminated. 
Between all variables considered by the risk Index, the length of surgery is the hazard factor most prone to discrepancies between institutions [5]. In our study, $65.4 \%$ of the surgery procedures were longer than the NNISS recommended time, what could be explained by the fact that the institution is a teaching hospital.

As with any patient, the risk of postoperative infections increases with the length of vascular access, the length of orotracheal intubation, the presence of indwelling catheters and the presence of devitalized tissue or fluid collections [3]. Also, the degree of immunosuppression, the need to additional anti-rejection therapy, and other infections like cytomegalovirus and hepatitis $\mathrm{C}$ could weaken the host defenses [14].

The high rate of infection found in this study, especially surgical site infections, suggests a demand for stricter prevention measures and control of health care-related infections in the institution, mostly during the perioperatory period.

Better detailed epidemiological studies are essential for evaluating health care-related infections surveillance actions and prognosis of solid organ transplant submitted patients.

\section{References}

1. Trzeciak S., Sharer R., Piper D., et al. Infections and severe sepsis in solid-organ transplant patients admitted from a universitybased ED. Am J Emerg Med 2004;22(7):530-3.

2. Garcia V.D. Registro brasileiro de transplantes. Associação brasileira de transplante de órgãos. Ano XI. Jan-Jul 2005.
3. Fishman J., Rubin R. Infections in organ transplant recipients. NEJM 1998;38:1741-51.

4. Candel F.J., Grima E., Matezans et al. Bacteremia and septic shock after solid-organ transplant. Transplant proceedings 2005; 37:4097-9.

5. Garner J.S., et al. CDC definitions for nosocomial infections, 1988. Am J Infect Control 1988;16(3):128-40.

6. Singh N., Wagener M., Obman A. Bacteremias in liver transplant recipients: shift toward gram-negative bacteria as predominant pathogens. Liver Transplantitation 2004;10(7):844-9.

7. Sénéchal M., LePrince P., Montcel S., et al. Bacterial mediatinitis after heart transplantation: clinical presentation, risk factors, and treatment. J Heart Lung Transplant 2004;23:165-70.

8. Emori T.G., Culver D.H., Horan T.C., et al. National nosocomial infections surveillance system (NNISS). Descriptions of surveillance methods. Am J Infect Control 1991;19:19-35.

9. Singh N., Chang F., Gayowski T. Fever in liver transplant recipients in the intensive care unit. Clin Transplantation 1999; $13: 504-11$.

10. Montoya J., Giraldo L., Efron B. Infectious complications among 620 consecutive heart transplant patients at Stanford University Medical Center. Clin Infect Dis 2001;33:629-40.

11. Lepelletier D., Perron S., Bizouarn P., et al. Surgical-site infections after cardiac surgery: incidence, microbiology, and risk factors. Infect Control Hosp Epidemiol 2005;26:466-72.

12. Taylor D, Edwards L, Mohacsi P. The registry of international society of heart and lung transplantation. Twentieth official adult heart transplantation report - 2003. J Heart Lung Transplant. 2003;22:616-24.

13. Ferraresso M., Bernardinelli L. Nosocomial infections in kidney transplant recipients: a retrospective analyses of a single center experience. Transplant Proc 2005;37:2495-6.

14. Snydman D. Epidemiology of infections after solid-organ transplantation. CID 2003:33(supll 1)S5-S8. 